\title{
Pheochromocytoma crisis with cyclic fluctuation in blood pressure mimics acute coronary syndrome
}

\author{
Mitsuhiro Kometani1, Takashi Yoneda1,2, Yuji Maeda1,3, Masashi Oe1, \\ Yoshimichi Takeda1, Takuya Higashitani ${ }^{1} 1$, Daisuke Aono', Asuka Yoshino1, \\ Shigehiro Karashima ${ }^{1}$ and Yoshiyu Takeda ${ }^{1}$
}

${ }^{1}$ Division of Endocrinology and Metabolism, Department of Internal Medicine, Kanazawa University Graduate School of Medicine, Kanazawa, Japan, ${ }^{2}$ Department of Health Promotion and Medicine of the Future, Kanazawa University, Kanazawa, Japan, and 32Department of Urology, Public Central Hospital of Matto Ishikawa, Hakusan, Japan
Correspondence should be addressed to T Yoneda

Email

endocrin@med.kanazawa-u. ac.jp

\section{Summary}

Pheochromocytoma crisis results from the sudden release of large quantities of catecholamines and leads to progressive multiple organ dysfunction. Here we report a case of pheochromocytoma crisis with symptoms associated with acute coronary syndrome (ACS) and severe fluctuations in blood pressure (BP). A 43-year-old Japanese man with hypertension (240/120 $\mathrm{mmHg}$ ) visited a general hospital for chest pain. Echocardiogram showed ST segment depression and blood test demonstrated elevated troponin T. However, emergent coronary angiography revealed normal findings. CT showed a large adrenal mass on the left side, which was suspected as the cause of chest pain and BP elevation. After the patient was transported to our hospital, his BP was found to oscillate between 70 and $240 \mathrm{mmHg}$, and level of consciousness was decreased. After hospitalization, he had a further decrease in consciousness, a rise in body temperature, and a gradual increase in the interval between the upper and lower systolic BP. His systolic BP varied between $30 \mathrm{mmHg}$ and $300 \mathrm{mmHg}$ at the intervals of 20-30 min. After a multimodality therapy, including $\alpha$-blocker and high dose fluid replacement, the fluctuation in his BP was gradually decreased and got stabilized after approximately $24 \mathrm{~h}$. Approximately 3 weeks later, he underwent left adrenalectomy. This case showed that pheochromocytoma with internal necrosis might be misdiagnosed as ACS. Furthermore, in cases with a large adrenal tumor and severe elevation or fluctuations of BP, pheochromocytoma should be suspected and treated with $\alpha$-blockers and fluid replacements as soon as possible prior to surgery.

\section{Learning points:}

- High catecholamine levels due to pheochromocytoma crisis might cause symptoms associated with acute coronary syndrome.

- Adrenal tumor with internal necrosis and the elevation or fluctuations of blood pressure should be suspected to be pheochromocytoma.

- If pheochromocytoma crisis is suspected, the specialist, such as an endocrinologist or a urologist, should intervene, and an $\alpha$-blocker treatment with adequate fluid replacement therapy should be initiated as soon as possible.

- Pheochromocytoma multisystem crisis (PMC) is a fatal condition characterized by multiple organ failure, severe blood pressure variability, high fever, and encephalopathy. This is an extremely rare subtype of a very rare disease such as pheochromocytoma. However, because the fatality rate of PMC is high, clinicians should be aware of the symptoms that mark its onset. 


\section{Background}

A catecholamine secreting pheochromocytoma is a relatively rare neuroendocrine tumor that arises from chromaffin cells of the adrenal medulla. Pheochromocytoma accounts for less than $1 \%$ of all causes of hypertension. In Japan, it accounts for approximately $10 \%$ of all adrenal incidentalomas (1). In a retrospective study from the Netherlands, Berends et al. reported that changes in diagnostic practices have contributed to the increase in the age-standardized incidence rate of pheochromocytomas (2).

Pheochromocytoma is associated with various cardiovascular diseases such as hypertension, arrhythmia, cardiomyopathy, and acute coronary syndrome (ACS) (3). The symptoms associated with ACS are occasionally found in patients with pheochromocytoma. Furthermore, the patients with pheochromocytoma crisis may experience chest discomfort, tachycardia and sweating due to sudden and massive release of catecholamines (4). In addition, pheochromocytoma multisystem crisis (PMC) is an extremely rare subtype of pheochromocytoma.

Here, we report a case of pheochromocytoma crisis that was initial diagnosed as a suspected ACS, followed by a final diagnosis with PMC.

\section{Case presentation}

A 43-year-old Japanese man had hypertension and hyperlipidemia for several years but received no treatment.
In the winter of 2014 , he presented to a primary care clinic for a sudden chest pain with blood pressure (BP) elevation $(240 / 120 \mathrm{mmHg})$ and cold sweating. Then he was referred to a general hospital because the cause of the pain could not be determined in the clinic. In the hospital, the ECG showed ST-segment depression, and laboratory tests demonstrated troponin $\mathrm{T}$ elevation, suggesting the presence of an acute coronary syndrome (ACS). However, coronary angiography (CAG) showed no significant stenosis. During CAG, a paroxysmal increase in BP was noted. In addition, CT imaging with iodinated contrast media showed an $86 \mathrm{~mm}$ left-sided adrenal tumor (Fig. 1A), which was a suspected cause of the chest pain and BP elevation. However, there were no specific therapeutic agents, such as phentolamine, in the hospital. Next, the patient was brought to our hospital for further examination and treatment for severe hypertension and the adrenal mass. Although we were informed after transportation, metoclopramide was used to treat his nausea just before transportation.

\section{Investigation}

When admitted to our hospital, the patient was awake and alert, with body temperature (BT): $37.6^{\circ} \mathrm{C}$, pulse rate: 133 bpm, BP: $129 / 67 \mathrm{mmHg}$, and $\mathrm{SpO}_{2}: 97 \%$ on supplemental oxygen $(2 \mathrm{~L} / \mathrm{min})$. The concentration of troponin $\mathrm{T}$ was $0.72 \mathrm{ng} / \mathrm{mL}$ (reference interval $<0.1$ ). In the emergency
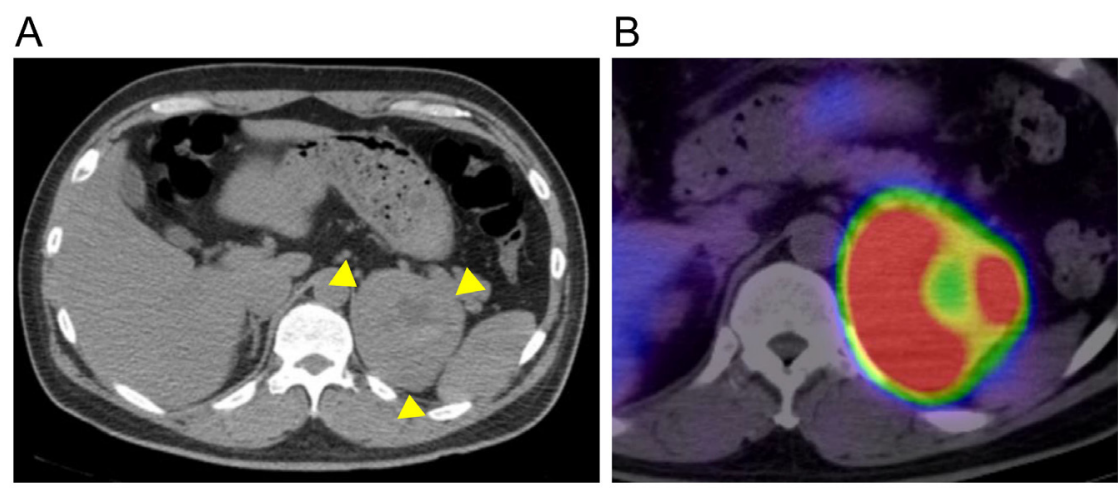

C

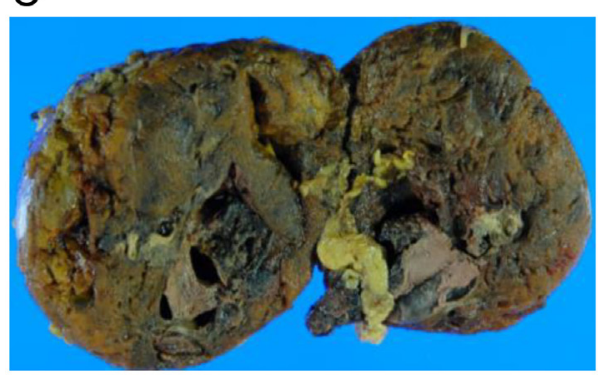

D

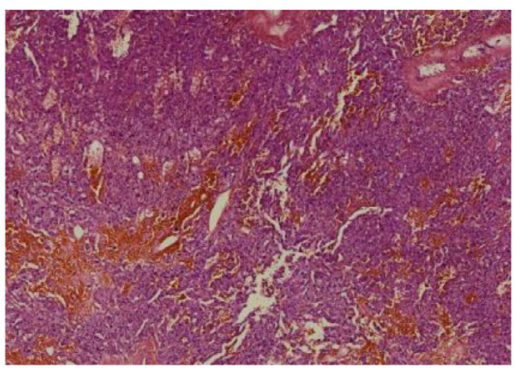

Figure 1

Imaging findings. (A) Computed tomography with iodinated contrast media shows internal necrosis of the large adrenal mass (yellow arrows). (B) 123I-metaiodobenzylguanidine scintigraphy shows extensive accumulation in the adrenal tumor. The site of necrosis appears like a doughnut with no accumulation. (C) Macroscopic and (D) microscopic findings of the tumor. 
room, he was sweating with headaches and nausea. We suspected pheochromocytoma due to the presence of a large adrenal tumor and paroxysmal BP elevation. First we injected phentolamine (5 mg) intravenously. Next, we started the continuous infusion of phentolamine ( $2 \mathrm{mg} / \mathrm{h})$, nicardipine $(5 \mathrm{mg} / \mathrm{h})$ and fluid replacement. However, his systolic BP began to oscillate between 70 and $240 \mathrm{mmHg}$, and his level of consciousness was 1 on the Japan Coma Scale (JCS) and 15 on the Glasgow Coma Scale (GCS). Results of the blood gas analysis revealed the following: $\mathrm{pH}$ 7.323, $\mathrm{pCO}_{2} 34.0 \mathrm{mmHg}, \mathrm{pO}_{2} 83.3 \mathrm{mmHg}$, and lactate $6.7 \mathrm{mmol} / \mathrm{L}$. The initial laboratory test results showed an increase in the white blood cell count and liver enzymes (Table 1). The ECG showed ST segment depression in many leads (Fig. 2), and echocardiography showed similar-inverted takotsubo cardiomyopathy (no image available).

\section{Treatment}

We suspected a hypertensive crisis due to the pheochromocytoma and sent him to our intensive care unit (ICU). After ICU admission, his consciousness worsened, corresponding to 10 on JCS and 12 on GCS,

Table 1 Laboratory test data.

\begin{tabular}{|c|c|c|c|}
\hline Test & At admission & $\begin{array}{l}12 \mathrm{~h} \text { after } \\
\text { admission }\end{array}$ & $\begin{array}{c}\text { Reference } \\
\text { interval }\end{array}$ \\
\hline WBC $\left(\times 10^{3} / \mu \mathrm{L}\right)$ & 24.0 & 20.5 & $3.3-8.8$ \\
\hline $\mathrm{RBC}\left(\times 10^{6} / \mu \mathrm{L}\right)$ & 5.55 & 5.29 & $4.5-5.5$ \\
\hline $\mathrm{Hb}(\mathrm{g} / \mathrm{dL})$ & 16.7 & 15.5 & $13.5-17.0$ \\
\hline $\mathrm{Ht}(\%)$ & 47.2 & 45.4 & $39.7-51.0$ \\
\hline Plt $\left(\times 10^{4} / \mu \mathrm{L}\right)$ & 303 & 293 & $130-350$ \\
\hline FDP-DD $(\mu \mathrm{g} / \mathrm{mL})$ & 3.2 & 5.3 & $<1.0$ \\
\hline CRP (mg/dL) & 0.2 & 3.6 & $<0.3$ \\
\hline РCT (ng/mL) & 0.2 & 2.5 & $<0.5$ \\
\hline T-Bil (mg/dL) & 1.0 & 0.7 & $0.3-1.2$ \\
\hline AST (U/L) & 0.2 & 124 & 13-33 \\
\hline ALT (U/L) & 0.2 & 99 & $8-42$ \\
\hline $\mathrm{LDH}(\mathrm{U} / \mathrm{L})$ & 0.3 & 516 & $119-229$ \\
\hline ALP (U/L) & 52 & 211 & $115-359$ \\
\hline $\mathrm{Na}(\mathrm{mEq} / \mathrm{L})$ & 143 & 144 & $135-149$ \\
\hline $\mathrm{K}(\mathrm{mEq} / \mathrm{L})$ & 3.1 & 4.3 & $3.5-4.9$ \\
\hline $\mathrm{Cl}(\mathrm{mEq} / \mathrm{L})$ & 135 & 106 & $96-108$ \\
\hline $\mathrm{Ca}(\mathrm{mg} / \mathrm{dL})$ & 143 & 9.1 & $8.0-10.5$ \\
\hline$P(\mathrm{mg} / \mathrm{dL})$ & 3.5 & 4.4 & $2.5-4.5$ \\
\hline BUN (mg/dL) & 103 & 19 & $8-22$ \\
\hline $\mathrm{Cr}(\mathrm{mg} / \mathrm{dL})$ & 9.4 & 1.8 & $0.6-1.0$ \\
\hline
\end{tabular}

ALP, alkaline phosphatase; ALT, alanine aminotransferase; AST, aspartate transaminase; $\mathrm{BUN}$, blood urea nitrogen; $\mathrm{Cr}$, creatinine; $\mathrm{CRP}, \mathrm{C}$ reactive protein; FDP-DD, fibrin degradation product-D-dimer; Hb, hemoglobin; $\mathrm{LDH}$, lactate dehydrogenase; PCT, procalcitonin; Plt, platelet; RBC, red blood cell; T-Bil, total birillubin; WBC, white blood cell.

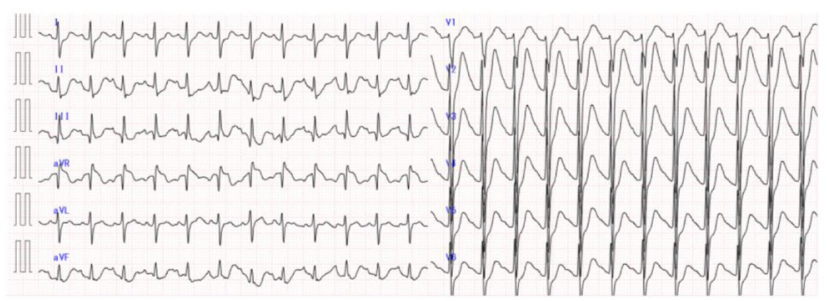

Figure 2

Electrocardiogram at admission.

his $\mathrm{BT}$ rose up to $39.1^{\circ} \mathrm{C}$, and the interval between the upper and lower systolic BP was gradually increased (Fig. 2). His systolic BP fluctuated from 30 to $300 \mathrm{mmHg}$ at internals of 20-30 min. He was intubated and sedated with propofol. After that, we added nitroglycerin for BP control and landiolol for heart rate control. Initially, we tried to control BP using antihypertensive adjustments drugs such as phentolamine and nicardipine; however, this treatment was not effective and BP fluctuation continued. Next, when the BP was decreased, we added more fluid replacements and human serum albumin, which resulted in a gradual stabilization of BP. While laboratory data on day 2 suggested multi-organ dysfunction and a suspected bacterial infection manifested with slight elevation of both C-reactive protein and procalcitonin, on day 3 it showed an improvement, and he was extubated on day 4. The patient was discharged from the ICU on day 8 . The plasma adrenaline and noradrenaline levels of day 2 were $5.90 \mathrm{ng} / \mathrm{mL}$ (normal: $<0.17 \mathrm{ng} / \mathrm{mL}$ ), and $360.00 \mathrm{ng} /$ $\mathrm{mL}(0.15-0.57 \mathrm{ng} / \mathrm{mL})$, respectively (Table 2$)$. However, plasma adrenaline and noradrenaline levels of day 5 were decreased to 0.05 and $2.40 \mathrm{ng} / \mathrm{mL}$, respectively. 123I-metaiodobenzylguanidine scintigraphy showed an extensive accumulation in the adrenal tumor. However, the site of necrosis appeared like a doughnut with no accumulation (Fig. 1B).

\section{Outcome and follow-up}

The patient was discharged from the ICU on day 8 (Fig. 3 ). The plasma adrenaline and noradrenaline levels of day 2 were $5.90 \mathrm{ng} / \mathrm{mL}$ (normal: < $0.17 \mathrm{ng} / \mathrm{mL}$ ), and 360.00 $\mathrm{ng} / \mathrm{mL}(0.15-0.57 \mathrm{ng} / \mathrm{mL})$, respectively (Table 2$)$. On day 18, the patient underwent left adrenalectomy (Fig. 3). The pathological findings showed no extracapsular extension and vein involvement (Fig. 1C and D). The Ki-67 index was less than $1 \%$. He was discharged on day 17 after the surgery. He is followed-up using 123I-metaiodobenzylguanidine scintigraphy and approximately once per year, and no recurrence has occurred so far. 
Table 2 Endocrinological data.

\begin{tabular}{l} 
Test \\
\hline Plasma adrenaline $(\mathrm{ng} / \mathrm{mL})$ \\
Plasma noradrenaline $(\mathrm{ng} / \mathrm{mL})$ \\
Urinary metanephrine $(\mathrm{mg} / \mathrm{day})$ \\
Urinary normetanephrine $(\mathrm{mg} /$ day $)$
\end{tabular}

\begin{tabular}{c}
\hline Hospital day $\mathbf{2}$ \\
\hline 5.90 \\
360.00 \\
1.70 \\
27.00 \\
\hline
\end{tabular}

\section{Discussion}

In pheochromocytoma, the excess of catecholamine causes chest discomfort due to an increase in myocardial oxygen consumption and cardiac afterload (5). In addition, high catecholamine levels due to pheochromocytoma crisis induce vasoconstriction of the coronary arteries leading to ECG abnormalities in the absence of coronary atherosclerosis (3). In the present case, ischemic heart disease was initially suspected based on the ECG abnormality and troponin T elevation. However, the cause of chest pain could not be determined using CAG. On the other hand, ultrasound echocardiogram showed Inverted takotsubo cardiomyopathy. Previous report said that takotsubo cardiomyopathy due to pheochromocytoma was occasionally found in patients diagnosed with ACS symptoms who lacked coronary artery stenosis

\begin{tabular}{c}
\hline Hospital day $\mathbf{6}$ \\
\hline 0.05 \\
1.90 \\
1.20 \\
17.00 \\
\hline
\end{tabular}

\begin{tabular}{c}
\hline After surgery \\
\hline$<0.01$ \\
0.35 \\
0.02 \\
0.19 \\
\hline
\end{tabular}

\begin{tabular}{c}
\hline Reference interval \\
\hline$<0.17$ \\
$0.15-0.57$ \\
$0.05-0.20$ \\
$0.10-0.28$
\end{tabular}

or spasm but showed pronounced BP variability (3). In pheochromocytoma, coronary artery stenosis may be rare even with ACS-like symptoms. However, it is necessary to perform coronary angiography to exclude ACS.

In our case, the presence of adrenal tumor was revealed prior to CAG. In general, adrenal tumors with internal necrosis are primary or metastatic adrenal carcinomas other than pheochromocytoma. Therefore, adrenal tumor with internal necrosis and high BP elevation should be suspected to be pheochromocytomas. In addition, when a pheochromocytoma is suspected, the specialist, such as an endocrinologist or a urologist, should be asked to intervene. This is because there are several drugs, such as metoclopramide, that are contraindicated for pheochromocytoma. Unfortunately, in addition to contrast media, metoclopramide was used in our case to treat nausea. Metoclopramide could have induced a
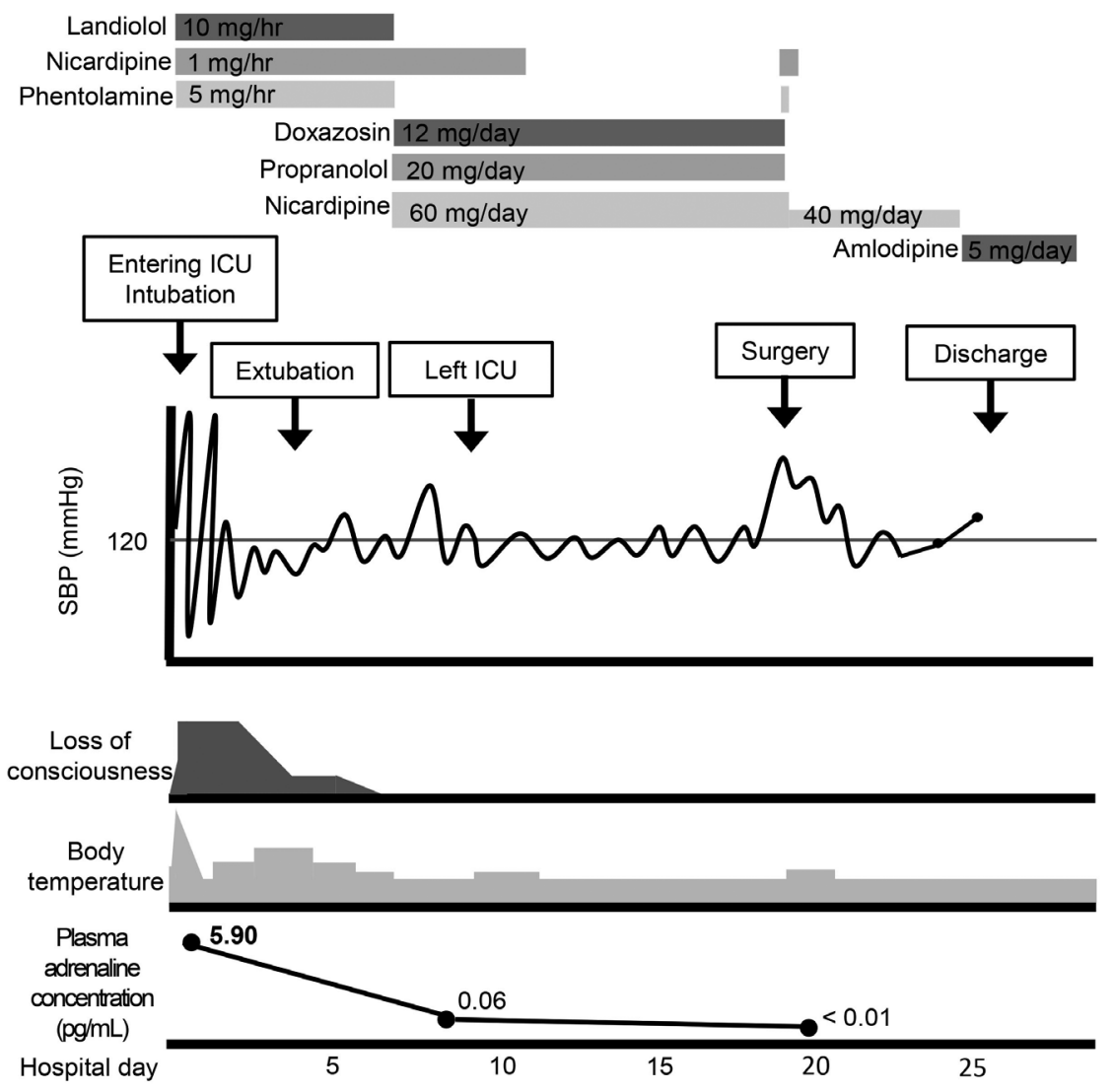

Figure 3

The clinical course of the case. SBP, systolic blood pressure. 
pheochromocytoma crisis just before transportation to our hospital.

Pheochromocytoma crisis is a hypertensive emergency that affects one or more organ systems, such as the brain, heart, kidney, and aorta. Although the goal of treatment for pheochromocytoma crisis is to remove the tumor, preoperative treatment to reduce perioperative risk must be undertaken. A retrospective cohort study of 97 patients with pheochromocytoma crisis has shown that the acute crisis should be stabilized prior to surgery for a successful management of the condition (6). Emergency resection of the pheochromocytoma without preoperative medical stabilization contributes to high surgical morbidity and mortality (6). Though similar cases have been reported previously, the treatment strategies were different. Oishi et al. have reported treating a similar case successfully with a selective $\alpha$-blocker (7). Kobal et al., in a study of nine cases, have reported the use of $\alpha$-blockers in all cases and their effectiveness in controlling BP fluctuation in five of the nine cases (8). Recently, Ionescu et al. have reported the successful treatment of pheochromocytoma with rapid alternating cycles of hypertension and hypotension using metirosine administration that inhibited catecholamine synthesis (9). In our case, the initial bolus injection followed by continuous infusion of phentolamine was effective, as was evident from the longer interval between BP fluctuations, compared to that reported previously. In addition, the high dose fluid replacement and albumin preparations therapy aided in stabilizing the patient's BP. Therefore, it is important to recognize pheochromocytoma as the cause of the cyclical fluctuations in BP at the earliest stage possible and start treatment with $\alpha$-blocker loading and sufficient fluid replacement.

Pheochromocytoma multisystem crisis (PMC) is a fatal condition characterized by multiple organ failure, severe blood pressure variability, high fever, and encephalopathy. In 1988, Newell et al. first reported three cases of PMC (10). Uchida et al. have reported the death of five out of eleven PMC patients (11). Severe BP fluctuation is one of the traits of PMC. In our case, the patient showed a decrease in his level of consciousness and an increase in BT as the time passed. Additionally, cyclical changes in BP were noted every 20-30 min. Based on these symptoms, he was diagnosed with PMC or pre-stage PMC. PMC is an extremely rare subtype of a very rare disease such as pheochromocytoma. However, because the fatality rate of PMC is high, clinicians must observe the patients' conditions carefully.

In summary, we reported a case of a pheochromocytoma crisis. High catecholamine level due to pheochromocytoma crisis might cause ACS associated symptoms. In addition, adrenal tumor with internal necrosis and high BP elevation should be suspected to be pheochromocytomas, and $\alpha$-blocker treatment and adequate fluid replacement therapy should be initiated as soon as possible. Furthermore, PMC is a fatal condition, and we need to pay close attention to the symptoms that may be suggestive of PMC.

\section{Declaration of interest}

The authors declare that there is no conflict of interest that could be perceived as prejudicing the impartiality of this case report.

\section{Funding}

This study was supported by the Japan Society for the Promotion of Science Grant (grant number 19K18003).

\section{Patient consent}

Written informed consent was obtained from the patient for publication of this case report and accompanying images.

\section{Author contribution statement}

$\mathrm{M} \mathrm{K}, \mathrm{T} \mathrm{Y}, \mathrm{Y} \mathrm{M}$, and $\mathrm{M} \mathrm{O}$ wrote the paper. $\mathrm{Y} \mathrm{T}, \mathrm{T} \mathrm{H}, \mathrm{D} \mathrm{A}$, and $\mathrm{A} \mathrm{Y}$ made the Figures and Tables. S K and $Y \mathrm{~T}$ supervised the case report. All authors reviewed the manuscript.

\section{Acknowledgements}

The authors thank Yukiko Takamiya and Chiyoko Takata for their secretarial assistance.

\section{References}

1 Ichijo T, Ueshiba H, Nawata H \& Yanase T. A nationwide survey of adrenal incidentalomas in Japan: the first report of clinical and epidemiological features. Endocrine Journal 202067 141-152. (https:// doi.org/10.1507/endocrj.EJ18-0486)

2 Berends AMA, Buitenwerf E, de Krijger RR, Veeger NJGM, van der Horst-Schrivers ANA, Links TP \& Kerstens MN. Incidence of pheochromocytoma and sympathetic paraganglioma in the Netherlands: a nationwide study and systematic review. European Journal of Internal Medicine 201851 68-73. (https://doi.org/10.1016/j. ejim.2018.01.015)

3 Prejbisz A, Lenders JW, Eisenhofer G \& Januszewicz A. Cardiovascular manifestations of phaeochromocytoma. Journal of Hypertension 2011 29 2049-2060. (https://doi.org/10.1097/HJH.0b013e32834a4ce9)

4 Sibal L, Jovanovic A, Agarwal SC, Peaston RT, James RA, Lennard TW, Bliss R, Batchelor A \& Perros P. Phaeochromocytomas presenting as acute crises after beta blockade therapy. Clinical Endocrinology 2006 65 186-190. (https://doi.org/10.1111/j.1365-2265.2006.02571.x)

5 Brown H, Goldberg PA, Selter JG, Cabin HS, Marieb NJ, Udelsman R \& Setaro JF. Hemorrhagic pheochromocytoma associated with systemic corticosteroid therapy and presenting as myocardial 
infarction with severe hypertension. Journal of Clinical Endocrinology and Metabolism 200590 563-569. (https://doi.org/10.1210/jc.20041077)

6 Scholten A, Cisco RM, Vriens MR, Cohen JK, Mitmaker EJ, Liu C, Tyrrell JB, Shen WT \& Duh QY. Pheochromocytoma crisis is not a surgical emergency. Journal of Clinical Endocrinology and Metabolism 201398 581-591. (https://doi.org/10.1210/jc.2012-3020)

7 Oishi S, Sasaki M, Ohno M, Umeda T \& Sato T. Periodic fluctuation of blood pressure and its management in a patient with pheochromocytoma. Case report and review of the literature. Japanese Heart Journal 198829 389-399. (https://doi.org/10.1536/ ihj.29.389)

8 Kobal SL, Paran E, Jamali A, Mizrahi S, Siegel RJ \& Leor J.

Pheochromocytoma: cyclic attacks of hypertension alternating with hypotension. Nature Clinical Practice: Cardiovascular Medicine 20085 53-57. (https://doi.org/10.1038/ncpcardio1054)

9 Ionescu CN, Sakharova OV, Harwood MD, Caracciolo EA,

Schoenfeld MH \& Donohue TJ. Cyclic rapid fluctuation of hypertension and hypotension in pheochromocytoma. Journal of Clinical Hypertension 200810 936-940. (https://doi.org/10.1111/j.1751-7176.2008.00046.x)

10 Newell KA, Prinz RA, Pickleman J, Braithwaite S, Brooks M,

Karson TH \& Glisson S. Pheochromocytoma multisystem crisis. A surgical emergency. Archives of Surgery 1988123 956-959. (https:// doi.org/10.1001/archsurg.1988.01400320042007)

11 Uchida N, Ishiguro K, Suda T \& Nishimura M. Pheochromocytoma multisystem crisis successfully treated by emergency surgery: report of a case. Surgery Today 201040 990-996. (https://doi.org/10.1007/ s00595-009-4165-8)

Received in final form 14 July 2020

Accepted 3 September 2020 